\title{
educação

\section{Desafios dos professores na mediação das brincadeiras de crianças com necessidades educacionais especiais na educação infantil}

\author{
Maria Madalena Moraes Sant'Anna ${ }^{1}$ \\ Faculdade Método de São Paulo, Brasil
}

\author{
EduARdo José ManZINIII \\ Universidade Estadual Paulista, Brasil \\ Dilmeire Sant'Anna Ramos VosgeraU ${ }^{\text {III }}$ \\ Pontifícia Universidade Católica do Paraná, Brasil
}

\author{
Vera Lúcia Messias Fialho Capellini ${ }^{\mathrm{IV}}$ \\ Universidade Estadual Paulista, Brasil
}

\author{
Luzia IARA Pfeiferv \\ Universidade de São Paulo, Brasil
}

\begin{abstract}
As diretrizes curriculares nacionais para a Educação Infantil priorizam o desenvolvimento das capacidades infantis de crianças até cinco anos, tendo o brincar como eixo norteador do aprendizado. O objetivo deste estudo foi identificar a percepção dos professores sobre as dificuldades para realizar e mediar brincadeiras para crianças com necessidades educacionais especiais (NEE) na Educação Infantil. A pesquisa foi de caráter qualitativo e utilizou a entrevista como procedimento de coleta de dados, para 31 professores de 11 crianças incluídas em sete centros de Educação Infantil de um município do Estado do Paraná - Brasil. As entrevistas foram sujeitas a análise de conteúdo, que indicou dois temas principais: mediação e dificuldades. Os resultados apontaram que professores brincam mais com estas crianças quando há dois professores em sala; demonstraram dificuldades de mediação nas brincadeiras com as crianças com Transtornos Globais do Desenvolvimento e Deficiência Intelectual, o que não ocorre junto às crianças com Deficiência Física. Os resultados indicam a necessidade de maior interação com os profissionais da saúde, de uma percepção mais individualizada das crianças com necessidades educacionais especiais, e de maior investimento na formação dos professores em serviço, quanto ao conhecimento de estratégias para mediar as brincadeiras.
\end{abstract}

Palavras-chave: Brincadeiras; Educação infantil; Necessidades educacionais especiais; Formação continuada 


\section{IN T RO D UÇ Ã O}

O Ministério da Educação e as Secretarias Estaduais de Educação brasileiros instituíram as Diretrizes Curriculares Nacionais para a Educação Infantil como documento norteador para a implementação das Políticas Municipais de Educação Infantil em 2010, definindo indicadores para tentar direcionar uma estrutura de base para essa etapa de educação das crianças no Brasil. Isto desencadeou a necessidade de alterações nas diretrizes e legislações estaduais e municipais para reorganizar e reestruturar a proposta da educação propiciada em creches e pré-escolas, envolvendo a faixa etária de zero a cinco anos (Resolução no 5, 2009). As abordagens propostas no currículo caracterizam-se pelo cuidado e pela educação, tendo como finalidade favorecer o desenvolvimento das capacidades infantis, com a função de cuidar e educar, por meio do desenvolvimento de brincadeiras e de cuidados básicos. O professor é considerado o mediador direto dessas crianças, responsável pelas brincadeiras, atividades de base para a infância, por meio das quais ocorrem caminhos eficazes para o processo de aprendizagem escolar (Navarro \& Prosdócimo, 2012). As brincadeiras podem ser desenvolvidas de diferentes maneiras, utilizando espaços e materiais do cotidiano escolar (Pozas, 2014; Tomé, 2014).

Define-se brincadeira como um conjunto de atividade humana, que necessita de aprendizagem, com influência do processo cultural e da significação social, e do mundo interno da criança, sendo caracterizada a partir do modo e do estado de espírito de como se brinca, do respeito às diferenças culturais, e da história de vida que a criança carrega consigo (Brougère, 1998). O brincar é compreendido como uma atividade cotidiana espontânea, subjetiva, para ser compartilhada, centrada na criatividade e apoiada na atitude, no interesse e na ação para que possa ser vivenciada, permitindo assim momentos de encontro, nos quais se possibilita a continuidade do desenvolvimento emocional, abrindo caminhos para um viver criativo (Ferland, 2006; Takatori, 2012). O brincar é marcado pelo processo da evolução do comportamento lúdico, por meio das fases e dos tipos de brincadeiras desempenhadas em cada idade cronológica, variando no modo e no estado de espírito de como se brinca, respeitando o mundo interno, as diferenças culturais e a história de vida que cada um traz (Brougère, 1998). É uma ação lúdica e subjetiva em que a criança tem a oportunidade de exercitar suas funções psicossociais, experimentar o novo, expressando a forma como pensa, organiza e constrói a sua realidade (Braccialli, Manzini, \& Reganhan, 2004; Ferland, 2006). Garantir esse espaço na Educação Infantil é vital para o seu processo de aprendizagem (Barros, 2009; Pozas, 2014).

Para uma brincadeira acontecer, devem ser disponibilizados objetos variados que fazem parte deste universo, denominados de brinquedos, os quais ajudam a criança a dar significado para as suas intenções lúdicas, imitando as rotinas de um adulto e construindo brincadeiras convencionais $\mathrm{e}$ não convencionais (Kishimoto, 2002, 2008). O brinquedo é um material estimulante que colabora na imaginação da criança, apesar de sabermos que ela não está preocupada com os resultados da brincadeira, mas sim impulsionada pelo prazer e pela motivação.

\section{Educação InClusiva no Brasil}

As políticas públicas para a Educação Especial no Brasil vêm buscando acompanhar as demandas internacionais, com a proposta de que, quanto mais precoce a sua iniciação, mais extenso e positivo o desenvolvimento das 
crianças, evitando formas segregacionistas e garantindo o direito de matrícula aos alunos com Necessidades Educacionais Especiais (NEE), os quais são identificados, nos documentos federais, como Público-Alvo da Educação Especial (PAEE) (Brasil, 2010).

No Brasil, esta inserção está embasada na constituição brasileira e detalhada no Ministério da Educação, que garante o acesso do público-alvo da Educação Especial à escola comum do ensino regular desde a Educação Infantil, e deve garantir a inclusão dos serviços de estudantes com deficiência, transtornos globais do desenvolvimento e altas habilidades ou superdotação, preferencialmente na rede regular de ensino, lembrando que esse público a cada dia torna-se mais presente na rotina da Educação Infantil (Brasil, 2008, 2011).

Além disso, na perspectiva de formação de professores, o aprendizado acadêmico deve focar práticas dentro de uma diversidade que incluam adaptações necessárias para o processo de ensino-aprendizagem, sem descontextualizar as atividades das crianças que necessitam de Educação Especial das dos demais colegas da sala (Brandão \& Ferreira, 2013; Glat \& Pletsch, 2012; Pacheco, Eggertsdóttir, \& Marinósson, 2007).

Apoiado nas diretrizes curriculares nacionais para a Educação Infantil (Resolução $\mathrm{n}^{\circ}$ 5, 2009), as quais propõem práticas pedagógicas cujo eixo norteador sejam as interações e as brincadeiras que possibilitem situações de aprendizagem mediadas para a elaboração da autonomia das crianças, considera-se fundamental investigar como essas brincadeiras acontecem com as crianças que necessitam de Educação Especial.

Para que as brincadeiras atinjam os propósitos para as crianças com NEE, é necessário melhorar o processo de mediação, favorecendo a interação professor-criança. Propostas pedagógicas baseadas nas necessidades individuais de cada criança e meios que permitam ao professor executar as estratégias específicas, para que a aprendizagem ocorra, também são necessários (Pelosi \& Nunes, 2009; Preto, 2009; Rocha \& Deliberato, 2012). No momento de propor as brincadeiras, é evidente a necessidade de conhecer as competências individuais de cada criança e o desenvolvimento sequencial do comportamento lúdico, para evitar os frequentes isolamentos das crianças com dificuldades de brincar (Ferland, 2006). Os professores da Educação Infantil, por meio da mediação, têm a responsabilidade de proporcionar qualidade nas vivências das brincadeiras (Brasil, 2009), considerando-as parte do processo de ensino e aprendizagem, pois a criança precisa de mediadores para conseguir brincar e garantir a aprendizagem vivida durante a Educação Infantil, que será o alicerce para a formação do indivíduo, base para as relações que construirá durante sua vida e seu desenvolvimento. Para tal, são necessárias a percepção e a mediação do professor de modo a possibilitar que essas crianças brinquem. Assim, esse professor terá também que, por meio de mediação, traduzir as intenções do amigo com necessidades educacionais especiais, para que este possa se sentir inserido no grupo (Evangelista \& Almeida, 2007; Tomé, 2014; Zortéa, 2011).

Nessa etapa do processo educacional, as abordagens pedagógicas apontam para o uso de atividades lúdicas e, também, indicam a elaboração de práticas educativas centradas nas necessidades individuais. Portanto, é essencial que o professor adquira, em sua formação, conhecimentos básicos sobre $o$ brincar e a forma como mediar essa atividade, usando estratégias adequadas às necessidades de cada criança, criando procedimentos para evitar os isolamentos e as segregações, visíveis em muitas atividades no processo escolar (Bassedas, Huguet, \& Solé, 1999; Navarro \& 
Prosdócimo, 2012).

$\mathrm{Na}$ Educação Infantil, a presença de crianças com quadros de deficiência, Transtornos Globais do Desenvolvimento, altas habilidades ou superdotação, enfim, de sujeitos com necessidades específicas, é cada dia mais evidente, assim como a necessidade de possibilitar um convívio pautado em um brincar prazeroso, respeitando o desenvolvimento afetivo e educacional, para viabilizar seu processo de aprendizagem (Rocha, Sant'Anna, \& Pelosi, 2017). Formar e preparar professores passou a ser necessário, já que, por muito tempo, o professor na Educação Infantil não era valorizado, sendo considerado um profissional de pouca qualificação, com ausência de projetos políticos pedagógicos que sustentassem a prática desse período de vida das crianças na escola (Kramer, 2005).

Para que as brincadeiras sejam verdadeiramente instauradas com qualidade no cotidiano da criança na Educação Infantil, é fundamental que o professor tenha a consciência de que, nesses momentos, as crianças estão elaborando, criando e recriando aquilo que sabem e vivenciam em seu processo de aprendizagem; portanto, a parceria entre profissionais da saúde e educação pode sustentar práticas embasadas na formação continuada em serviço (Sant'Anna \& Manzini, 2018), com mediações adequadas entre professor e criança planejadas a partir das necessidades e possibilidades da criança (Ferland, 2006; Pozas, 2014). Assim, confirmando o brincar como uma atividade única e prioritária na Educação Infantil, este estudo propõe-se a identificar a percepção do professor sobre as dificuldades para realizar e mediar as brincadeiras das crianças com NEE.

\section{MÉTODO}

Este é um estudo qualitativo, aprovado pelo Comitê de Ética da UNESP/Marília sob o Parecer no 0538/2012, que descreveu e interpretou as informações por meio de análise de conteúdo, utilizando a técnica tal como proposta por Bardin (2010).

\subsection{Participantes}

Foi investigada a percepção de 31 professores, sobre as dificuldades que encontram para realizar e mediar as brincadeiras com 11 crianças com NEE, todas matriculadas em 2013 em sete Centros Municipais Educação Infantil (CMEI) de uma cidade de médio porte do Paraná - Brasil. Estes centros implantavam a proposta de inclusão vigente no país, com base em laudos clínicos dos profissionais da saúde e relatos de família.

As 11 crianças com NEE apresentavam diferentes diagnósticos clínicos, os quais foram classificados em três tipos de deficiências: 1 . Deficiência Física; 2. Deficiência Intelectual; e 3. Transtorno Global do Desenvolvimento. A Deficiência Física (DF) e a Deficiência Intelectual (DI) são consideradas como "aquelas que têm impedimentos de longo prazo, de natureza física, mental ou sensorial que, em interação com diversas barreiras, podem ter restringida sua participação plena e efetiva na escola e na sociedade" (Brasil, 2008, p. 11). O Transtorno Global do Desenvolvimento (TGD) se refere ao "quadro de alterações no desenvolvimento neuropsicomotor, comprometimento nas relações sociais, na comunicação, estereotipias motoras. Incluem-se nessa definição alunos com autismo clássico, síndrome de Asperger, síndrome de Rett, transtorno desintegrativo da infância (psicoses) e transtornos invasivos sem outra especificação" (Brasil, 2008, p. 11).

O perfil das 11 crianças com NEE encontrase descrito no Quadro 1. Estas crianças frequentavam o ensino de período integral, sob a responsabilidade dos 31 professores 
QUADRO 1

Caracterização das Crianças com NEE

\begin{tabular}{|c|c|c|c|c|c|}
\hline Participantes & Gênero & Idade & Diagnóstico Clínico & Tipografia & Professores \\
\hline $\mathrm{C} 1$ & $\mathrm{~F}$ & 3 & Pé torto congênito & Deficiência Física & $\mathrm{P} 1, \mathrm{P} 2$ \\
\hline $\mathrm{C} 2$ & M & 3 & $\begin{array}{l}\text { Limitação cognitiva e } \\
\text { comportamental * }\end{array}$ & $\begin{array}{l}\text { Transtorno Global do } \\
\text { Desenvolvimento }\end{array}$ & P3, P4, P8, P9 \\
\hline $\mathrm{C} 3$ & M & 2 & $\begin{array}{l}\text { Limitação cognitiva e } \\
\text { comportamental }\end{array}$ & $\begin{array}{l}\text { Transtorno Global do } \\
\text { Desenvolvimento }\end{array}$ & $\begin{array}{l}\text { P5, P6, P7, } \\
\text { P10, P11 }\end{array}$ \\
\hline $\mathrm{C} 4$ & M & 4 & Nanismo & Deficiência física & $\begin{array}{l}\text { P12, P13, } \\
\text { P14, P15 }\end{array}$ \\
\hline C5 & $\mathrm{F}$ & 5 & PC - Hemiparesia & Deficiência física & P16 \\
\hline $\mathrm{C} 6$ & M & 5 & $\begin{array}{l}\text { Limitação cognitiva e } \\
\text { comportamental }\end{array}$ & $\begin{array}{l}\text { Transtorno Global do } \\
\text { Desenvolvimento e } \\
\text { Deficiência Intelectual }\end{array}$ & P17, P18 \\
\hline $\mathrm{C} 7$ & $\mathrm{~F}$ & 4 & $\begin{array}{c}\text { Síndrome Cornelia de } \\
\text { Lange }\end{array}$ & $\begin{array}{l}\text { Transtorno Global do } \\
\text { Desenvolvimento com } \\
\text { Deficiência Física e } \\
\text { Intelectual }\end{array}$ & $\begin{array}{l}\text { P19, P20, } \\
\text { P22, P24 }\end{array}$ \\
\hline $\mathrm{C} 8$ & $\mathrm{~F}$ & 4 & $\begin{array}{l}\text { Paralisia de Membros } \\
\text { Inferiores }\end{array}$ & Deficiência Física & $\mathrm{P} 21$ \\
\hline C9 & M & 5 & $\begin{array}{l}\text { Limitação cognitiva e } \\
\text { comportamental }{ }^{*}\end{array}$ & $\begin{array}{l}\text { Transtorno Global do } \\
\text { Desenvolvimento }\end{array}$ & P25, P26 \\
\hline $\mathrm{C} 10$ & M & 3 & $\begin{array}{l}\text { Amputação de membro } \\
\text { inferior }\end{array}$ & Deficiência física & $\begin{array}{l}\text { P27, P29, } \\
\text { P30, P31 }\end{array}$ \\
\hline $\mathrm{C} 11$ & M & 1,5 & Pé torto congênito & Deficiência física & P28 \\
\hline
\end{tabular}

incluídos nos sete CMEI, e tinham idades entre um ano e meio e cinco anos.

Todos os 31 professores eram graduados em Pedagogia; 26 com Pós-Graduação Lato Sensu, sendo que, destes, somente dois tinham formação em Educação Especial.

\subsection{Procedimentos de COLETa de dados}

Os dados foram coletados por meio de entrevistas. O roteiro das questões foi avaliado por um comitê de especialistas, para verificar se atendia aos propósitos da pesquisa. A partir desta análise, e realizados os ajustes necessários, o roteiro da entrevista ficou composto por oito grupos de questões:

1. Quais são as brincadeiras das crianças no parque? E você poderia me dar exemplos de como elas brincam? Elas têm preferência?

2. E com os brinquedos que trazem de casa, como brincam?

3. As crianças brincam no parque e com brinquedos que trazem de casa sozinhas ou existe alguma participação do professor?

4. O que os professores fazem nesta participação?

5. Você encontra dificuldade para realizar a atividade de brincar no parque com as crianças com necessidades educacionais especiais em sua turma? Quais? E com brinquedos que trazem de casa? Quais?

6. Em sua opinião, qual a maior dificuldade que a criança com deficiência apresenta quando brinca? Na sua opinião, existem brinquedos na escola que facilitam o brincar destas crianças?

7. No seu planejamento, como você denomina 
a atividade de brincar?

8. Você gostaria de acrescentar algo sobre o assunto tratado?

Os 31 professores participantes deste estudo foram contatados e as entrevistas agendadas e realizadas, individualmente, na própria escola, em salas disponíveis nos horários previamente marcados.

As entrevistas foram realizadas por meio de diálogos entre pesquisador e entrevistado, buscando a maior interação possível. Foram gravadas em áudio, tendo-se optado pela forma de transcrição integral, com ajustes para o uso de normas ortográficas (Manzini, 2003, 2008).

2.3 Procedimentos PARA ANálise dos DADOS

As respostas dos professores passaram por uma análise qualitativa, utilizando a técnica de análise de conteúdo proposta por Bardin
(2010), sendo esta implementada com o auxílio do software Atlas Ti, a partir de duas categorias: a mediação e as dificuldades nas brincadeiras.

\section{RESULTADOS}

Os professores das crianças com NEE do município envolvido neste estudo relataram encontrar mais dificuldade para melhorar o desempenho nas brincadeiras das crianças com DI e TGD.

$\mathrm{O}$ Quadro 2 refere-se às principais dificuldades das crianças e dos professores na realização das atividades de brincadeiras propostas no planejamento pedagógico desenvolvido, citadas pelos 31 professores.

A partir das descrições no Quadro 2 e da análise proposta por Bardin (2010), duas categorias foram analisadas: mediação e dificuldades nas brincadeiras para crianças com NEE.

QUADRO 2

Principais Dificuldades de Professores e Crianças nas Atividades de Brincadeiras, Conforme Planejamento Pedagógico

\section{Com enfoque no comportamento da criança}

- Que fiquem atentos nas atividades.

- Que diminuam a agitação da sala.

- $\quad$ Que não fiquem mexendo em tudo, o tempo todo.

- Que respeitem os combinados com o grupo.

- Que permaneçam na sala.

- Que não batam e não empurrem os amigos.

- Que permaneçam nas brincadeiras.

\section{Com enfoque no comportamento do professor}

- $\quad$ Como obter informações sobre estratégias que podem ser utilizadas para aumentar o interesse das crianças nas atividades.

- Como diminuir a assistência propiciada devido à necessidade de segurar a criança muito próximo ao corpo para poder participar de brincadeiras mais sentadas em sala.

- Como manter contacto com os pais.

- Como ensinar a brincar. 
3.1 MEDIAÇÕES REALIZADAS PELOS PROFESSORES DE EDUCAÇÃO INFANTIL

$\mathrm{Na}$ categoria sobre as mediações realizadas pelos professores, na rotina da Educação Infantil dos centros infantis pesquisados, os relatos indicaram que estas mediações aconteciam de diferentes maneiras, nos diferentes tipos de brincadeiras, a partir dos problemas comportamentais descritos no Quadro 2. Os professores apoiavam-se em seus planejamentos, estruturados de acordo com as diretrizes curriculares nacionais, sem elaborar nenhuma estratégia específica para as crianças com NEE em seus projetos semanais. Muitas vezes, entretanto, improvisavam algumas ações individualmente, de acordo com suas necessidades, para tentar facilitar a brincadeira para a criança com NEE, sentindo falta de um auxílio mais específico, tanto para pensar o planejamento quanto de ter mais um professor em sala para atuar em parcerias. Além disso, apresentavam dificuldades para estabelecer as mediações a partir dos comportamentos descritos no Quadro 1.

P1 - Eu acho que falta um pouco tanto de uma estrutura física quanto pedagógica para a gente, de um auxílio, de uma orientação a mais, para termos mais propriedade e poder auxiliar e trabalhar com mais propriedade, conseguindo ajudar mais essas crianças.

P26 - Eu sinto dificuldade nas estratégias devido ao sentido de comportamento agressivo dele $\mathrm{e}$ outras coisas mais, que me faz tirar o foco do grupo. Às vezes eu fico devendo para ele, e infelizmente, e dependendo do dia, a turma acaba perdendo um pouco de mim também.

A frequência do brincar com as crianças com NEE no parque era diária, durante um período que variava entre 20 e 60 minutos, previamente definido no planejamento semanal ou de acordo com as propostas do dia de cada turma, sendo este um espaço livre. Alguns Centros de Educação Infantil não tinham espaço e brinquedos suficientes, mas, na maioria, havia escorregador, balanço, pneus soltos no pátio, bolas, motocas e carrinhos. Algumas vezes, deixavam as crianças brincar livremente, sem nenhuma mediação direta; em outros momentos, percebiam a necessidade, mas não conseguiam ter uma conduta específica.

P25 - Porque os outros eu já consigo sanar as dificuldades, agora no caso dele seria mais específico, mais junto, brincar mais com ele. Não excluindo ele, deixando ele no grupo, mas desde que a auxiliar estivesse junto. E isto não acontece sempre, só algumas vezes.

As estratégias de mediação das professoras eram selecionadas a partir da maioria das crianças da sala, e não necessariamente considerando as com NEE, tanto na brincadeira do parque quanto do brinquedo trazido de casa. Observou-se uma lacuna de uma percepção mais individualizada, principalmente das crianças que apresentavam Transtornos Globais do Desenvolvimento. Consideraram imperativa a compreensão da necessidade de cada uma, para que fosse proposta uma atividade compatível com seu desenvolvimento no planejamento, possibilitando conhecer e identificar os momentos em que deveriam estar próximos ou mais distantes, ou aqueles em que poderiam envolver as demais crianças do grupo.

Para melhorar as mediações e enfrentar as dificuldades relatadas no Quadro 2, todos os 31 professores entrevistados apontaram a necessidade de dois professores no parque, justificada pela dificuldade em manter o grupo, bem como em direcionar a atenção necessária, ocasionando intermitentes desvantagens para as crianças com NEE ou para as crianças 
com desenvolvimento típico. Relataram as dificuldades evidentes das crianças com TGD e DI em interagir com as outras crianças, com frequente isolamento, necessitando sempre de mediação. Afirmaram, também, a necessidade de maior envolvimento entre os profissionais da saúde e da educação para compartilhar o cotidiano da criança na escola e receber orientações que poderiam contribuir em suas estratégias.

P11 - Quando ele não traz o brinquedo, ele quer o dos outros, ele vai pegar, ele faz o que os outros fazem, mas a diferença é que ele não negocia, ele puxa, e a gente fala "Olha aqui, vamos pedir emprestado para o amigo", mas ele não tem paciência, bate, morde, e aí a gente tem dificuldade de saber como fazer para ensinar ele a pedir, a esperar.

P3 - Ele usa fralda ainda, ele não para quieto, fica batendo na porta, é difícil de controlar, tem que ter sempre alguém junto com ele, a gente está preocupada, como é que vai ficar uma professora só na sala, e as outras crianças?

P19 - É quando a gente fica sozinha, a dificuldade é dar atenção a ele. Como a gente também não tem experiência, não sabe o que é certo, então a gente sempre teve essa falta de apoio para planejar as atividades. Qual é a melhor maneira? A gente acha que é assim, mas não sei se é.

Entrevistados de cinco CMEI propuseram realizar a mediação das brincadeiras com brinquedos trazidos de casa com o propósito de socializar, compartilhar, mas com estratégias de execução diferenciadas. Somente uma CMEI não adotou esta atividade, pois a adesão dos familiares em mandar o brinquedo foi muito baixa, resultando na desistência desta atividade. Em outro caso, devido ao fato de a criança estar no berçário, esta atividade não foi incluída no planejamento.

Os relatos indicaram que, uma vez por semana, em dia preestabelecido, algumas crianças traziam os brinquedos. As finalidades variavam de acordo com a idade da criança e, também, com a forma como cada CMEI desenvolvia as atividades propostas nos planejamentos. Dos 31 professores entrevistados, 14 afirmaram que cinco crianças do público-alvo da Educação Especial não tinham hábito de trazer os brinquedos; que o bilhete com essa instrução era enviado no início do ano letivo e muitas mães se esqueciam de mandar. As demais professoras relataram que a frequência com que as crianças com NEE traziam o brinquedo de casa era pequena e que, quando traziam, as com TGD e DI tinham grandes dificuldades de encontrar parceiros; para encontrá-los, dependiam de uma mediação do professor.

P8 - Ele não participa, ele quer bater, ele quer tirar o brinquedo que está com o outro; se o dele está no chão, ele vai pegar o do outro. No parque ele corre por toda escola, não brinca, tem dificuldade de ficar com os outros. Quando está junto, se a gente não cuida, ele só bate.

P24 - Sim, na sexta-feira, mas é muito raro ela trazer. Os pais, eles não mandam brinquedo, mas para ela não ficar sem, a gente acaba pegando brinquedo do CMEI, que a gente tem um baú e a gente deixa livre pra ela escolher o que ela quer, e quase todas as vezes ela prefere a boneca mesmo.

\subsection{DificuldadES NAS BRINCADEIRAS PARA AS CRIANÇAS COM NEE}

$\mathrm{Na}$ categoria dificuldades com as brincadeiras, consideraram-se o comportamento do professor e as vivências das brincadeiras, pois, ao rever somente as dificuldades dos professores, as das crianças com NEE seriam minimizadas. Esses entraves existem, principalmente, por falta de 
mediações e estrutura tanto física quanto de profissionais. Foram incluídas dificuldades dos professores e das crianças em brincar (Quadro 2), sendo citado como fator desencadeante o desconhecimento das reais necessidades educacionais. A falta de preparo acadêmico e em serviço dos professores para atuar com a criança em processo de inclusão escolar inviabiliza o trabalho. Além disso, considerar que os professores não tinham formação acadêmica é algo inesperado, uma vez que todas as professoras cursaram Pedagogia e somente oito não possuíam formação de Pós-Graduação Lato Sensu.

P18 - A maior dificuldade é fazer ele entender mesmo, porque às vezes as crianças elaboram uma brincadeira e ele não consegue entender. Por exemplo, um amigo falou assim: "Pega o telhado, pega o telhado", mas o telhado era o pedaço do colchão pra colocar em cima, e ele não entende a brincadeira de faz-de-conta, ele só entende o sentido literal mesmo. Ele falou para mim: "Professora, vou achar um telhado", e ele saiu duas vezes para achar um telhado e falou que não achou e eu falei "O telhado é o colchãozinho, é para fazer de conta que é um telhado para pôr aqui”. Mas ele demorou bastante tempo para entender e o amigo veio e pegou o colchãozinho e ele ficou fora da brincadeira.

P19 - É pra serem dois professores, mas na realidade são raras as situações que estão ficando as duas professoras na sala. Então eu tenho que dar conta das outras 17 crianças, se eu for ficar toda hora "Volta aqui para brincar com a tia, volta aqui que eu vou contar uma história”, eu não realizo as atividades com eles. Então, quando eu dou brinquedo, ela sempre brinca, agora quando eu estou contando uma história, estou explicando a brincadeira, ela fica no cantinho dela brincando com as coisinhas dela.
As dificuldades do professor nas brincadeiras no parque relacionam-se às crianças com TGD e DI; alguns apontaram que as singularidades de cada criança deveriam ser observadas. As maiores dificuldades foram: fazer parceiros nas atividades propostas pelo grupo; ter pouco interesse na brincadeira compartilhada; falta de experiência do professor em perceber as reais necessidades; o professor estar sozinho na sala; e o fato de os próprios professores da instituição não acreditarem na proposta de inclusão.

P17 - Desde o começo, a gente ficava sozinha. Até que daí viu que não tinha condição. Então, até ficarmos em duas professoras, ficava pulando, um dia era uma que ficava comigo, outro dia era outra, então ela não tinha referência. Depois que começou uma fixa, então, aos poucos, ela foi conseguindo, foi conseguindo fazer as adaptações, ter maior controle.

P19 - É uma falha nossa não planejar as atividades para ela, porque, se estamos contando uma história, como ela não fala, a gente usa algumas outras estratégias, como figura ou o próprio livro. Mas eu não coloco no planejamento, vai ali na hora, adaptando o que podemos.

As dificuldades do professor, com o comportamento da criança no parque, referemse aos relatos sobre a sua interação com os brinquedos e com os amigos. As limitações motoras envolvendo, principalmente, as crianças com DF e as dificuldades de comunicação das crianças com TGD são consideradas um impedimento no momento de desfrutar destas brincadeiras.

P3 - eu acho que é o interagir com as outras crianças.

P2 - primeiro insegurança, e aí depois a parte motora mesmo, é mais difícil para eles... E eu 
chamo para ir para o parque, e ele vai, chega lá, ele fica sozinho, isolado, ele não brinca com os outros, se chega algum amigo perto dele para brincar, ele ignora, ele não tem muito contato visual.

Os resultados demonstraram que os principais obstáculos do professor nas brincadeiras, tanto do parque quanto com o brinquedo trazido de casa, referiram-se às estratégias específicas a partir de suas necessidades, sendo complicado traçá-las devido ao número de crianças em sala e ao fato de estarem sozinhos, principalmente em relação às crianças com TGD, que apresentavam dificuldades em acompanhar o projeto pedagógico do grupo e em brincar com os colegas.

P8 - Às vezes a gente só fica falando "não" para ele, sem ter tempo de sentar e brincar.

P19 - Eu não tenho conhecimento sobre a síndrome dela, quais as limitações. Só que eu não tenho pós em Educação Especial. Se não é legal para ela, ela vai levantar e vai lá na caixinha de brinquedos, que a maioria é tudo de encaixe e ela gosta de ficar lá, ela brinca no espelho. Então tem hora que ela não participa das atividades, que às vezes ela até demonstra uma certa irritação; então a gente deixa ela, e quando tem uma atividade que gosta, ela volta.

P25 - Nunca pensei numa estratégia assim específica para ele. O que vai acontecendo, vou pensando na hora e vou tentando mais socializar ele mesmo. Nunca pensei no brincar exatamente com ele, a partir do que ele sabe e consegue.

\section{D I SCUSS Ão}

$\mathrm{Na}$ descrição das categorias mediação e dificuldades nas brincadeiras para crianças com $N E E$ foi percebido que tanto as dificuldades apresentadas nas brincadeiras pelas crianças, quanto as dos professores em proporcionar a mediação revelam que o nível de assistência dado para aumentar a participação é maior para as crianças com TGD. Neste estudo, evidenciouse a importância de mediações adequadas para garantir o processo de aprendizagem que acontece no momento das brincadeiras. Para que uma criança usufrua dos momentos lúdicos, os mediadores devem conhecer suas competências reais e saber o momento de estar presente e o momento de estar ausente, para possibilitar que o processo de aprendizagem e as vivências lúdicas se estabeleçam e instalem (Brougère,1998; Pozas, 2014).

Percebeu-se, por meio dos relatos, que os professores envolvidos neste estudo não apresentaram dificuldades para planejar e mediar as brincadeiras propostas em seus projetos pedagógicos para crianças com $\mathrm{DF}$, conhecendo o momento e o porquê de brincarem de acordo com o grau de desenvolvimento da criança, indo ao encontro das propostas das diretrizes curriculares nacionais para a Educação Infantil. A especificação clara da finalidade da brincadeira e da razão pela qual é necessário garanti-la no processo educacional das crianças pressupõe as interações e as brincadeiras como eixos norteadores para a prática pedagógica (Brasil, 2009).

Os conceitos de mediação apresentados por Debortoli (2009), Zortéa (2011) e Navarro e Prosdócimo (2012) avaliam a necessidade de haver dois professores nos grupos, uma vez que, devido ao número de crianças envolvidas, o professor não consegue atender à singularidade de cada uma. Dois professores podem conduzir o processo de aprendizagem com mais qualidade, elaborando um projeto pedagógico individualizado para a criança com NEE a partir de suas reais necessidades, das características de seu desenvolvimento e de seu processo de aprendizagem.

Ficam evidentes as dificuldades que os 
professores apresentam no momento de realizar brincadeiras para as crianças com TGD e DI em processo de inclusão, quando não conhecem as necessidades individuais das crianças. Necessitam de orientações sobre como agir e estar com estas crianças, para que consigam brincar utilizando as propostas oferecidas nas atividades lúdicas, fato também confirmado nos estudos de Debortoli (2009), Silva (2007), Oliveira (2008) e Sant'Anna e Manzini (2018), que destacaram a importância da parceria educação e saúde para que esses procedimentos aconteçam.

Para isto, a Formação Continuada em Serviço para os professores é recomendável, pois a maioria dos educadores que atua hoje não cursou, em sua graduação, disciplinas que abordassem a problemática para as necessidades educacionais da Educação Especial em suas especificidades. Além disso, apesar de a maioria dos professores ter uma formação Lato Sensu, isto não garante qualidade na prática desses profissionais. Neste estudo, apenas duas professoras fizeram PósGraduação Lato Sensu voltada para a Educação Especial, sendo necessário investir-se na qualidade das formações oferecidas (Capelini \& Rodrigues, 2009).

Conhecer a percepção dos professores sobre como acontecem as brincadeiras das crianças com NEE é fundamental, pois, a partir destes dados, as suas prioridades podem ser (re) definidas para melhorar a participação das crianças nas brincadeiras propostas para o seu grupo. É necessário identificar estratégias que favoreçam a realização das brincadeiras, que permitam avaliar o desempenho deste públicoalvo, identificando o grau de participação e os obstáculos que existam para que possam participar nas propostas de Educação Infantil (Brasil, 2009; Lopes, Correia, \& Aguiar, 2016).

O diálogo entre crianças e professor, na Educação Infantil, acontece de diferentes formas, e muitas das dificuldades no momento de brincar são evidentes, podendo ocorrer com variadas modalidades de brincadeiras em seu cotidiano. Isso sugere que, no momento de propor brincadeiras em seus planejamentos, a necessidade de conhecer as particularidades da criança e o desenvolvimento sequencial do comportamento lúdico são prioritários, principalmente para evitar os frequentes isolamentos de crianças incapazes de brincar, as quais necessitam, essencialmente, da mediação do professor para que o seu desenvolvimento aconteça (Bassedas et al., 1999; Brasil, 2010; Zabalza, 1998).

É importante que o professor priorize o conhecimento de como esse comportamento lúdico se instala na criança e como se apresenta nas diferentes etapas do desenvolvimento, pois somente após esse conhecimento solidificado estará capacitado a planejar para que a criança consiga desfrutar das brincadeiras esperadas para cada etapa de sua evolução, elaborando um projeto pedagógico individualizado e construindo estratégias de mediação a partir das suas reais necessidades (Bassedas et al., 1999; Sant’Anna \& Manzini, 2018).

\section{CONSIDERAÇÕES FINAIS}

Percebe-se, a partir dos resultados apresentados, que os 31 professores envolvidos na pesquisa tinham disponibilidade para estar com as crianças com NEE nos momentos de brincadeiras, e que elas brincavam a partir da mediação do professor. Os professores indicaram que, quando estão em dois na sala, a qualidade da atenção dada à criança é melhor, e a maioria demonstrou, nas falas, que não conhecia as singularidades de cada criança de seu grupo. Encontraram dificuldade em definir estratégias de acordo com as particularidades de cada criança com TGD e DI, que permaneciam mais isoladas.

Por meio dos relatos, conclui-se que as reflexões sobre a importância do brincar para 
a criança com NEE, bem como a presença dos professores na Educação Infantil foram comprovadamente valorizadas, mas as estratégias utilizadas pelo professor ainda necessitam de mais investimentos para possibilitar e garantir um planejamento educacional individualizado.

Para a efetivação de estratégias baseadas em projetos pedagógicos individualizados, que atinjam as demandas das crianças na escola comum do ensino regular, é imperativo aumentar-se o número de professores em sala e o investimento para subsidiar a Formação Continuada em Serviço, viabilizando ao professor conhecer as especificidades de cada criança em relação à sua deficiência, ampliando as chances de melhorar as estratégias para a sua participação nas brincadeiras propostas na Educação Infantil.

\section{REFERÊ NCIAS}

Bardin, L. (2010). Análise de conteúdo. Lisboa: Edições 70.

Barros, F. C. O. M. (2009). "Você sabe como a gente brinca? De mamãe, de pega-pega, de escolinha, de médico, de neném..." - A teoria histórico-cultural: O brincar como atividade essencial para o desenvolvimento infantil. In F. C. O. M. Barros (Org.), Cadê o brincar? Da educação infantil para o ensino fundamental (pp. 103-134). São Paulo: Cultura Acadêmica.

Bassedas, E., Huguet, T., \& Solé, I. (1999). Aprender e ensinar na educação infantil. Porto Alegre: Artmed.

Braccialli, L. M. P., Manzini, E. J., \& Reganhan, W. G. (2004, novembro). Contribuição de um programa de jogos e brincadeiras adaptadas para a estimulação de habilidades motoras em alunos com deficiência física. Anais da 27a Reunião Anual da ANPEd (pp. 1-16), Caxambu, MG, Brasil. Recuperado de http://27reuniao.anped.org.br/gt15/t154. pdf

Brandão, M. T., \& Ferreira, M. (2013). Inclusão de crianças com necessidades educativas especiais na educação infantil. Revista Brasileira de Educação Especial, 19(4), 487502. Recuperado de http://www.scielo.br/ pdf/rbee/v19n4/v19n4a02.pdf

Brasil. (2008). Ministério da Educação. Secretaria de Educação Especial. Política nacional de Educação Especial na perspectiva da educação inclusiva. Brasília: MEC/SEESP.

Brasil. (2009). Ministério da Educação. Resolução $n^{\circ}$ 5, de 17 de dezembro de 2009. Fixa as Diretrizes Curriculares Nacionais para a Educação Infantil.

Brasil. (2010). Ministério da Educação. Secretaria de Educação Básica. Diretrizes curriculares nacionais para a educação infantil. Brasília: MEC.

Brasil. (2011). Casa Civil. Decreto n. 7.611, de 17 de novembro de 2011. Dispõe sobre a Educação Especial, o atendimento educacional especializado e dá outras providências. Recuperado de http:// www.planalto.gov.br/ccivil 03/ ato20112014/2011/decreto/d7611.htm

Brougère, G. (1998). A criança e a cultura lúdica. Revista da Faculdade de Educação, 24(2), 103-116. Recuperado de http://www.revistas. usp.br/rfe/article/download/59630/62727

Capelini, V. L. M. F., \& Rodrigues, O. M. P. R. (2009). Concepções de professores acerca dos fatores que dificultam o processo da educação inclusiva. Educação, 32(3), 355-364. Recuperado de http:// revistaseletronicas.pucrs.br/ojs/index.php/ faced/article/view/5782

Debortoli, J. A. O. (2009). Educação infantil e conhecimento escolar: Reflexão sobre a presença do brincar na educação de crianças pequenas. In A. Carvalho, \& J. A. O. Debortoli (Orgs.), Brincar(es) (pp. 6582). Belo Horizonte: UFMG.

Evangelista, M. M. T. T., \& Almeida, A. M. F. P. M. (2007). A construção do projeto 
político-pedagógico na Escola Municipal de Educação Infantil (EMEI) "Florípes Silveira de Souza". Revista Simbio-Logias, 1(2), 1-18.

Ferland, F. (2006). O modelo lúdico: O brincar, a criança com deficiência física e a terapia ocupacional ( $3^{\text {a }}$ ed.). São Paulo: Roca.

Glat, R., \& Pletsch, M. D. (2012). Inclusão escolar de alunos com necessidades especiais ( $2^{\text {a }}$ ed.). Rio de Janeiro: EDUERJ.

Kishimoto, T. M. (2002). Bruner e a brincadeira. In T. M. Kishimoto (Org.), O brincar e suas teorias (pp. 139-153). São Paulo: Cengage Learning.

Kishimoto, T. M. (2008). Jogo, brinquedo, brincadeira e a educação (11 a ed.). São Paulo: Cortez.

Kramer, S. (2005). Formação de profissionais de educação infantil: Questões e tensões. In M. L. A. Machado (Org.), Encontros e desencontros em educação infantil ( $2^{\mathrm{a}}$ ed., pp. 117-132). São Paulo: Cortez.

Lopes, L., Correia, N., \& Aguiar, C. (2016). Implementação do direito de participação das crianças em contexto de jardim de infância: As percepções dos educadores. Revista Portuguesa de Educação, 29(2), 81108. Recuperado de http://www.scielo.mec. pt/pdf/rpe/v29n2/v29n2a05.pdf

Manzini, E. (2003). Considerações sobre a elaboração de roteiro para entrevista semiestruturada. In M. C. Marquezine, M. A. Almeida, \& S. Omote (Orgs.), Colóquios sobre pesquisa em Educação Especial (pp. 1125). Londrina: Eduel.

Manzini, E. (2008). Uso da entrevista em dissertações e teses sobre educação (Tese livre-docência). Universidade Estadual Paulista - UNESP, Marília, SP, Brasil.

Navarro, M. S., \& Prosdócimo, E. (2012). Brincar e mediação na escola. Revista Brasileira de Ciências do Esporte, 34(3), 633648. Recuperado de http://www.scielo.br/ $\mathrm{pdf} / \mathrm{rbce} / \mathrm{v} 34 \mathrm{n} 3 / \mathrm{v} 34 \mathrm{n} 3 \mathrm{a} 08 . \mathrm{pdf}$

Oliveira, Z. R. (2008). Educação infantil: Fundamentos e métodos ( $4^{\mathrm{a}}$ ed.). São Paulo:

\section{Cortez.}

Pacheco, J., Eggertsdóttir, R., \& Marinósson, G. L. (2007). Caminhos para a inclusão: Um guia para o aprimoramento da equipe docente. Porto Alegre: Artmed.

Pelosi, M. B., \& Nunes, L. R. O. P. (2009). Caracterização dos professores itinerantes, suas ações na área de tecnologia assistiva e seu papel como agente de inclusão escolar. Revista Brasileira de Educação Especial, 15(1), 141-154. Recuperado de http://www. scielo.br/pdf/rbee/v15n1/10.pdf

Pozas, D. (2014). Criança que brinca mais aprende mais: A importância da atividade lúdica para o desenvolvimento cognitivo infantil. Rio de Janeiro: SENAC.

Preto, V. O. (2009). Adaptação de livros de literatura infantil para alunos com deficiência visual (Dissertação de mestrado não publicada). Faculdade de Filosofia e Ciências, Universidade Estadual Paulista, Marília, SP, Brasil.

Rocha, A. N. D. C., \& Deliberato, D. (2012, janeiro/março). Tecnologia assistiva para a criança com paralisia cerebral na escola: Identificação das necessidades. Revista Brasileira de Educação Especial, 18(1), 7192. Recuperado de http://www.scielo.br/ pdf/rbee/v18n1/a06v18n1.pdf

Rocha, A. N. D. C., Sant'Anna, M. M. M., \& Pelosi, M. (2017). Terapia ocupacional: Ações colaborativas no contexto escolar. In J. P. Oliveira, A. N. D. C. Rocha, R. K. Miura, \& E. S. Rodrigues (Orgs.), Desenvolvimento infantil na escola e inclusão: Ações pedagógicas e intersetoriais (pp. 141-160). Curitiba: Editora CRV.

Sant'Anna, M. M. M., \& Manzini, E. J. (2018, janeiro/junho).Identificação denecessidades iniciais para formação continuada de professores da educação infantil para o público-alvo da Educação Especial. Revista Educação Especial em Destaque, 2(5), 29-45. Recuperado de http://periodicos.ufes.br/ $\underline{\text { REED/article/view/20980 }}$ 
Silva, A. C. (2007). Formação continuada em serviço e prática pedagógica (Dissertação de mestrado). Faculdade de Educação, Universidade de Brasília, Brasília, DF, Brasil.

Takatori, M. (2012). O brincar na terapia ocupacional: Um enfoque na criança com lesões neurológicas. São Paulo: Zagodoni.

Tomé, M. F. (2014). A educação infantil foi para a escola, e agora? Introdução ao estudo da gestão escolar na educação infantil (11 ${ }^{\mathrm{a}}$ ed.). Jundiaí: Paco Editorial.

Zabalza, M. A. (1998). Qualidade em educação infantil. Porto Alegre: Artmed.

Zortéa, A. M. (2011). Inclusão na educação infantil: As crianças nos (des)encontros com seus pares. Porto Alegre: Redes Editora.
CHALLENGES FACED BY TEACHERS ON MEDIATING THE PLAY OF CHILDREN WITH SPECIAL EDUCATIONAL NEEDS IN EARLY CHILDHOOD EDUCATION

\section{Abstract}

The National Education Standards for Early Childhood prioritize skills development of children up to five years old, taking play as a guideline of learning. The objective of this study was to identify the perceptions of teachers on the difficulties to perform and mediate the play of children with special educational needs (SEN) in early childhood education. It is a qualitative research, which collected data using interviews with 31 teachers of 11 children in seven Early Childhood Education centers, in Paraná state town. The interviews were analysed using content analysis procedures that revealed two main themes: mediation and difficulties. The results indicated that teachers play more with these children when there are two teachers in the room; they demonstrated difficulties in mediation when playing with children with pervasive developmental disorders and intellectual disabilities, which does not happen with children with physical disabilities. There is a need of greater interaction with health professionals, more individualized perception of children with special educational needs, and greater investment in in-service teacher training, mainly in what comes to knowing strategies to mediate play.

KeY-words: Playing; Early childhood education; Special educational needs; In-service teacher training programs 
LES DÉFIS DES ENSEIGNANTS DANS LA MÉDIATION DES JEUX DES ENFANTS AUX BESOINS ÉDUCATIFS SPÉCIAUX DANS L'ÉDUCATION DE ENFANTS

\section{RÉSUMÉ}

Les directives de programmes scolaires du Brésil pour l'éducation des enfants priorisent le développement des capacités des enfants jusqu'à cinq ans, ayant les jeux comme axe de guidage de l'apprentissage. Le but de cette étude a été d'identifier la perception des professeurs à propos des difficultés à effectuer et faire la médiation des jeux pour les enfants ayant besoins éducatifs spéciaux dans l'éducation des enfants. La recherche était qualitative, et il a été employé l'interview comme procédure pour faire la collecte de données avec 31 enseignants de 11 enfants inclus dans sept Centres d'Éducation des Enfants d'une ville de l'État de Paraná, Brésil. Les entretiens ont été soumis à une analyse de contenue celui a indiqué deux thèmes principaux: médiation e difficultés. Les résultats ont souligné que les enseignants jouent mieux avec ces enfants lorsqu'il y a deux enseignants ensembles dans la salle, ainsi qu'ils éprouvent des difficultés de médiation dans les jeux avec les enfants qui ont des Troubles du Développement Global et Déficience Intellectuelle, ce que n'arrive pas auprès des enfants avec Déficience Physique. Les résultats indiquent la nécessité d'une meilleure interaction entre les professionnels de la santé, une perception plus individualisée des enfants ayant besoins éducatifs spéciaux et un plus grand investissement dans les formations des enseignants en service par rapport à la connaissance des stratégies pour faire la médiation des jeux.

Mots-CLÉs : Jeux ; Éducation des enfants ; Besoins éducatifs spéciaux; Formation continue

${ }^{\text {I }}$ Pós-graduação Lato Sensu de Terapia Ocupacional: Uma Visão Dinâmica em Neurologia, Faculdade Método de São Paulo - FAMESPSP, Brasil. ORCID: 0000-0002-3446-3455

${ }^{\text {II }}$ Programa de Pós-Graduação em Educação, Departamento de Educação Especial, Universidade Estadual Paulista - UNESP/ Marília, Brasil. ORCID: 0000-0002-7157-8227

III Programa de Pós-Graduação em Educação, Pontifícia Universidade Católica do Paraná - PUCPR, Brasil. ORCID: 00000002-9508-0888

IV Programas de Pós-Graduação em Psicologia do Desenvolvimento e da Aprendizagem e Docência para a Educação Básica, Departamento de Educação, Universidade Estadual Paulista - UNESP/Bauru, Brasil. ORCID: 0000-0002-9184-8319

${ }^{v}$ Departamento de Neurociências e Ciências do Comportamento, Faculdade de Medicina de Ribeirão Preto, Universidade de São Paulo/Ribeirão Preto, Brasil. ORCID: 0000-0002-1826-1968

Toda a correspondência relativa a este artigo deve ser enviada para:

Maria Madalena Moraes Sant'Anna

Avenida Garibaldi Deliberador, 545, bloco 1, apto 34

Recebido em fevereiro de 2018

Londrina RP, CEP 86050-280, Brasil.

E-mail: madasantanna2@gmail.com 